\title{
RESEARCH
}

Open Access

\section{Achieving equitable uptake of handwashing and sanitation by addressing both supply and demand-based constraints: findings from a randomized controlled trial in rural Bangladesh}

\author{
Sarker Masud Parvez ${ }^{1 * \dagger}$ (D, Musarrat Jabeen Rahman ${ }^{1 \dagger}$, Rashidul Azad $^{1}$, Mahbubur Rahman ${ }^{1}$, Leanne Unicomb ${ }^{1}$,
} Sania Ashraf ${ }^{2}$, Momenul Haque Mondol ${ }^{3}$, Farjana Jahan ${ }^{1}$, Peter J. Winch ${ }^{4}$ and Stephen P. Luby ${ }^{5}$

\begin{abstract}
Background: Supply driven programs that are not closely connected to community demand and demand-driven programs that fail to ensure supply both risk worsening inequity. Understanding patterns of uptake of behaviors among the poorest under ideal experimental conditions, such as those of an efficacy trial, can help identify strategies that could be strengthened in routine programmatic conditions for more equitable uptake. WASH Benefits Bangladesh was a randomized controlled efficacy trial that provided free-of cost WASH hardware along with behavior change promotion. The current paper aimed to determine the impact of the removal of supply and demand constraints on the uptake of handwashing and sanitation behaviors across wealth and education levels.

Methods: The current analysis selected 4 indicators from the WASH Benefits trial — presence of water and soap in household handwashing stations, observed mother's hand cleanliness, observed visible feces on latrine slab or floor and reported last child defecation in potty or toilet. A baseline assessment was conducted immediately after enrolment and endline assessment was conducted approximately 2 years later. We compared change in uptake of these indicators including wealth quintiles $(\mathrm{Q})$ between intervention and control groups from baseline to endline.

\footnotetext{
* Correspondence: parvez@icddrb.org; parvezmasud1980@gmail.com

† Sarker Masud Parvez and Musarrat Jabeen Rahman are Co-primary author with equal contribution

'Environmental Intervention Unit, Infectious Diseases Division, International

Centre for Diarrhoeal Disease Research, Bangladesh (icddr,b), Dhaka, Bangladesh

Full list of author information is available at the end of the article
}

(C) The Author(s). 2021 Open Access This article is licensed under a Creative Commons Attribution 4.0 International License, which permits use, sharing, adaptation, distribution and reproduction in any medium or format, as long as you give appropriate credit to the original author(s) and the source, provide a link to the Creative Commons licence, and indicate if changes were made. The images or other third party material in this article are included in the article's Creative Commons licence, unless indicated otherwise in a credit line to the material. If material is not included in the article's Creative Commons licence and your intended use is not permitted by statutory regulation or exceeds the permitted use, you will need to obtain permission directly from the copyright holder. To view a copy of this licence, visit http://creativecommons.org/licenses/by/4.0/ The Creative Commons Public Domain Dedication waiver (http://creativecommons.org/publicdomain/zero/1.0/) applies to the data made available in this article, unless otherwise stated in a credit line to the data. 
(Continued from previous page)

Results: For hand cleanliness, the poorest mothers improved more [Q1 difference in difference, DID: 16\% (7, 25\%)] than the wealthiest mothers [Q5 DID: 7\% (-4, 17\%)]. The poorest households had largest improvements for observed presence of water and soap in handwashing station [Q1 DID: 82\% (75, 90\%)] compared to the wealthiest households [Q5 DID: 39\% (30,50\%)]. Similarly, poorer household demonstrated greater reductions in visible feces on latrine slab or floor [Q1DID, - 25\% $(-35,-15)$ Q2: $-34 \%(-44,-23 \%)$ than the wealthiest household [Q5 DID: $-1 \%(-11,8 \%)$. For reported last child defecation in potty or toilet, the poorest mothers showed greater improvement [Q1-4 DID: 50-54\% (44,60\%)] than the wealthier mothers [Q5 DID: 39\% (31, 46\%).

Conclusion: By simultaneously addressing supply and demand-constraints among the poorest, we observed substantial overall improvements in equity. Within scaled-up programs, a separate targeted strategy that relaxes constraints for the poorest can improve the equity of a program.

Trial registration: WASH Benefits Bangladesh: ClinicalTrials.gov, identifier: NCT01590095. Date of registration: April 30, 2012 'Retrospectively registered'.

Keywords: WASH benefits, Uptake, Equity, Wealth quintiles, Sanitation, Handwashing

\section{Background}

Despite overall health improvements occurring globally, health remains unevenly distributed with poorer populations having worse health than wealthier populations [1, 2]. Public health interventions can further widen the health gap if they produce greater benefit among wealthier populations, while vulnerable populations in poorer quintiles miss out on the health improvements $[3,4]$.

In low- and middle-income countries (LMICs), the burden of illnesses fall disproportionately on the poorest and illness associated costs represent a higher proportion of income for the poorest relative to the wealthiest [5]. The poorest are also least likely to receive preventive interventions or have access to life-saving treatments [6]. Targeting the poorest can also be cost-effective. Poorest children are likely to contribute more pathogens to the environment than wealthier children [7]. A recent report found that the investment of $\$ 1$ through public health interventions averts 1.8 times more deaths among the poor compared with an investment directed at the non-poor [8]. Hence, exploring which intervention components reach the poorest and least educated are key aspects of determining the public health impact of interventions.

Globally, an estimated 1.6million deaths and 105 million disability-adjusted life years (DALY) are attributable to inadequate water, sanitation and hygiene (WASH) [9]. In nearly all LMICs, the poorest have the lowest levels of WASH conditions such as lowest sanitation coverage and the lowest levels of improved water supply coverage $[10,11]$. In Bangladesh, the wealthiest households have more than three-fold higher access to adequate sanitation than the poorest households [12]. The poorest and the least educated are also less likely to have soap and water at a dedicated handwashing location and less frequently practice handwashing than their wealthier and more educated counterparts [13-16]. Wealthier and more educated households are more likely to practice microbiologically effective household water treatment $[17,18]$.

Supply-driven WASH interventions prioritize the provision of WASH infrastructure. However, without adequate behavior change promotion, supply-driven efforts, such as building or subsidizing latrine construction, may be ineffective and unsustainable [1921]. Residents of many communities in India preferred defecating in the open over using latrines, even when they had access to one [22, 23]. In sub-Saharan Africa, around a quarter of handpumps, which are a major source of drinking water, are not functional due to lack of maintenance [24]. Supply-driven approaches can increase inequity by benefitting the physically and politically connected who are more likely to receive the supplies and more able to arrange maintenance [19].

Another segment of WASH interventions emphasize demand-based approaches. Scaled-up programs in the WASH sector, such as community-led total sanitation (CLTS) and social marketing are examples of strategies that have gained prominence in the recent decades and have emphasized demand-generation effort rather than alleviating supply constraints. CLTS programs place complete responsibility of construction of latrines on the community, and this demand-driven behavior promotion approach has achieved high levels of coverage in studies in Asia and Africa [25-27]. It may be effective on the whole, but it is not clear if this strategy is equitable. For example, as part of CLTS in Indonesia, the poorer households were the least likely to improve their sanitation conditions [28]. Sanitation evaluations elsewhere have also shown how the last people to adopt an intervention are the poorest and least educated [29-33]. Social marketing is another demand-driven strategy applying commercial marketing techniques to promote public health products and behaviors. This strategy can 
also disproportionately benefit the least poor who can more easily access better products to improve their behaviors [34-38]. In Kenya for example, social marketing of inexpensive chlorine water treatment product resulted in good product penetration and use, but the poorest and least educated were least likely to benefit from this intervention [39].

There is a difference in household level effort required to manage municipality supplied running water that comes directly to the house through taps and toilets connected to municipal sewage systems and thus removes feces from the environment in contrast to a household level system for water and fecal management that has no public component. Household-level WASH interventions, whether supply or demand driven, can put enormous burden on the poorest households by expecting them to purchase all of their infrastructure and supplies and to practice demanding behaviors every day. Supply-driven programs that have not been closely connected to community demand and demand-driven programs that are weak on the supply end both risk worsening inequity. Understanding patterns of uptake of behaviors among the poorest under ideal experimental conditions, such as those of an efficacy trial, can help identify strategies that could be strengthened in routine programmatic conditions for more equitable uptake.

The intervention in the WASH Benefits Bangladesh trial addressed both demand and supply-side constraints. The trial evaluated the health impact of different WASH and nutrition interventions [40]. Since WASH Benefits Bangladesh was an efficacy trial the implementation team aimed to maximize intervention fidelity, access and uptake [41, 42]. The project team provided WASH hardware (enabling hardware such handwashing stations and latrines) free-of-cost and ensured maintenance services. This was coupled with interpersonal behavior change activities by community health promoters (CHPs). The CHPs promoted behavioral recommendations and associated messages developed from the IBM-WASH model [43], to generate demand for WASH behaviors among the target audience [40, 41, 44].CHPs made frequent visit to all households promoting the health behavior messages and troubleshooting WASH hardware-related problems that the participants faced.

After 2 years of WASH Benefits intervention, mean uptake of sanitation and handwashing practices were substantially higher among intervention communities compared to controls [44]. However, improvements in mean levels can mask wealth disparities [45]. We hypothesized that, the least educated and poorest populations had the same level of improvement over time as those better-off. Therefore, the analysis presented in this paper aimed to determine whether uptake of handwashing and sanitation behaviors was equitable across different wealth and education levels.

\section{Methods}

\section{Study setting and population}

The WASH Benefits Bangladesh trial was a cluster randomized trial conducted in rural villages of four districts (Gazipur, Kishoreganj, Mymensingh, Tangail) in central Bangladesh [40, 46]. The study population consisted of pregnant women in their first two trimesters of pregnancy and their children who were expected to be born within approximately 6 months of the survey conducted at baseline. The selection criteria were not based on their wealth. The enrollment began in May 2012 and the study enrolled a total of 5551 pregnant women in 720 geographic clusters.

\section{WASH benefits intervention}

The details of WASH Benefits study methods are described elsewhere [40, 46].WASH Benefits identified 8 mothers living in close proximity to each other, to form a cluster and then formed eight geographical clusters that were grouped to form a block. The study comprised of 90 blocks (720 clusters) in total (participants enrolment and retention summary details in supplementary Table 1). The trial randomly allocated the group of eight geographically proximate clusters to one of the eight study arms that included two control and six intervention arms (Supplementary Table 2): water (W) arm, sanitation $(\mathrm{S})$ arm, handwashing $(\mathrm{H})$ arm, nutrition $(\mathrm{N})$ arm, water, sanitation and handwashing combined arm (WSH) and water, sanitation handwashing and nutrition combined arm (WSHN). We established a buffer zone of a minimum of $15 \mathrm{~min}$ walking distance that separated two adjacent clusters so that the intervention would not spillover from cluster to another.

Household from the intervention arms received WASH technologies and nutrition supplements. Supplementary Table 1 details the technological supplies and key behavioral messages for intervention households in the WASH Benefits Trial. For the purposes of the current paper, we analyzed data from only the arms that had sanitation and handwashing interventions (single or combined). The details regarding water treatment and nutrition interventions are described elsewhere $[40,46]$. The technologies provided in the sanitation arm included hardware such as concrete ring-based dual pit latrines that had a slab, water seal and walls for privacy. The sanitation intervention also included a potty for young children and a sani-scoop for removal of child feces from the environment to safe disposal in the latrine. The handwashing intervention included the provision of a handwashing station, soapy water bottle and detergent-one station was provided for the latrine and another for the kitchen area. The intervention was implemented in phases over 24 months. In the control 
arm no intervention and behavioral change messages were delivered.

The intervention also included communication to promote adoption of the behavioral recommendations delivered with high fidelity, by local community health promoters (CHPs) [41]. CHPs were nominated by community members from the same locality to enhance acceptability at household level. Each intervention cluster had its own CHP. Intensive training of CHPs was conducted at the beginning of the project followed by periodical refreshers training throughout the intervention period.

CHPs encouraged regular use of the hardware components through regular household visits, approximately twice a week. The behavioral recommendations were to treat drinking water for children aged $<36$ months, use latrines for defecation and the removal of human and animal feces from the compound, wash hands with soap at critical times around food preparation, defecation, and contact with feces.

\section{Data collection}

Hardware presence, functionality and behavioral uptake were measured as part of assessment at baseline (conducted immediately after the enrolment of the pregnant women), midline (end of the first year of intervention) and endline (end of the second year of intervention when the child age was about 21-30 month). Baseline data collection was conducted from May 2012 to July 2013, and endline data collection was conducted from November 2014 to November 2015. Assessment visits were unannounced prior to the individual household visits.

Assessment tools were designedbased on the project indicators which were developed, piloted and revised through substantial feedback, comments and discussions with national and international experts [41]. The field workers collected data based on self-reports and objective observations.

\section{Data analysis}

We analysed three observed and one reported uptake indicators collected during baseline and compared with endline behaviours. First, the trained enumerators collected data on observed hand cleanliness of mothers since contaminated hands. Second, they collected data on presence of water and soap in the handwashing station. Third, they collected data on visible feces and lastly they collected self-reported data on whether the child defecated in a potty or latrine as a measure of potty-use.

For analyses of handwashing variables, we merged the data from all handwashing intervention arms $(\mathrm{H}, \mathrm{WSH}$, $\mathrm{N}+\mathrm{WSH}$ ) and for analyses of sanitation variables, we merged all sanitation arms (S, WSH, N+WSH). We generated descriptive summaries for socio-demographic characteristics of our respondents by study arms and wealth quintiles and education levels. We computed the wealth using principal component analysis (PCA) based on household characteristics and ownership of assets. Then we generated five wealth quintiles (Q1-Q5) where Q1 was the lowest and Q5 the wealthiest quintile. We compared observed and reported respondent practices between baseline and endline across wealth quintiles. We also compared observed and reported respondent practices between baseline and endline across education levels. We calculated difference in difference (DID) using generalized linear models (GLM) to compare changes from baseline to endline between households receiving interventions with the control group and adjusted for clustering using a clustered sandwich estimator. In addition, we conducted a three-way interaction between intervention, time and socio-demographic indicators using GLM to directly assess if the impact of the interventions were modified by maternal education and wealth quintiles.

\section{Protection of study participants}

Respondents in the enrolled households (children's mothers/caregivers) provided informed consent before interviews. The study protocol was reviewed and approved by human subject committees at the International Centre for Diarrhoeal Disease Research, Bangladesh (icddr,b), (PR\#11063), University of California, Berkeley (2011-09-3652), and Stanford University (25863).

\section{Results}

The intervention and control arms had similar sociodemographic characteristics (Table 1). However, these characteristics differed between wealth quintiles (Table 2). In Q1, approximately $32 \%$ of mothers lacked any formal education while there were only $2.4 \%$ in Q5. The mean monthly household income increased across the wealth quintiles (mean (SD) Q1:73(1.1) \& Q5: \$252(5)). Only 18\% of households had electricity in Q1 while more than $90 \%$ of the household had this facility in Q5. Among Q1-3, no families had refrigerator whereas $38 \%$ of households from Q5 reported refrigerator facilities. Around 27\% of the household from the highest quintile (Q5) owned a motorcycle where none had among the first two quintiles (Table 2).

For observed hand cleanliness, all mothers across education levels, and wealth status showed marked improvement from baseline to endline in the handwashing intervention groups. However, the largest improvements occurred among the youngest mothers compared to older mothers (DID: 12\%, CI: 1, 23\%), uneducated mothers (DID: 17\%, CI: 7, 27\%) compared to mothers 
Table 1 Baseline characteristics of participants and households according to study arms

\begin{tabular}{|c|c|c|c|c|c|}
\hline \multirow[t]{3}{*}{ Characteristics } & \multicolumn{5}{|c|}{$\mathrm{n}(\%)$ or mean $\pm \mathrm{SD}$} \\
\hline & Control & Sanitation & Handwashing & $\mathrm{W}+\mathrm{S}+\mathrm{H}^{\mathrm{a}}$ & $\mathrm{W}+\mathrm{S}+\mathrm{H}+\mathrm{N}^{\mathrm{b}}$ \\
\hline & $N=1382$ & $N=696$ & $N=688$ & $N=703$ & $N=686$ \\
\hline Maternal age & $23.5 \pm 5.0$ & $23.7 \pm 5.2$ & $23.8 \pm 5.4$ & $24.3 \pm 5.5$ & $23.8 \pm 5.5$ \\
\hline \multicolumn{6}{|l|}{ Maternal education } \\
\hline No education & $206(15)$ & $115(17)$ & $101(15)$ & $100(14)$ & $116(17)$ \\
\hline Up-to primary & $440(32)$ & $218(31)$ & $221(32)$ & $223(32)$ & $225(33)$ \\
\hline Above primary & $736(53)$ & $363(52)$ & $366(53)$ & $380(54)$ & $345(50)$ \\
\hline \multicolumn{6}{|l|}{ Paternal education } \\
\hline No education & $406(30)$ & $209(30)$ & $221(32)$ & $221(32)$ & $203(30)$ \\
\hline Up to Primary & $412(30)$ & $204(29)$ & $211(31)$ & $198(28)$ & $228(33)$ \\
\hline Above primary & $560(41)$ & $282(41)$ & $255(37)$ & $281(40)$ & $254(37)$ \\
\hline Monthly household income (US\$) & $133 \pm 2.8$ & $131 \pm 3.8$ & $127 \pm 3.6$ & $140 \pm 4.2$ & $137 \pm 4.1$ \\
\hline People/household & $4.7 \pm .06$ & $4.7 \pm .08$ & $4.7 \pm .08$ & $4.7 \pm .08$ & $4.7 \pm .08$ \\
\hline Children $<3$ years /household & $0.2 \pm .01$ & $0.2 \pm .02$ & $0.2 \pm .02$ & $0.2 \pm .02$ & $0.2 \pm .02$ \\
\hline Children $<3$ years /compound & $0.7 \pm .02$ & $0.6 \pm .03$ & $0.7 \pm .03$ & $0.7 \pm .03$ & $0.7 \pm .03$ \\
\hline Own home & $1357(98)$ & $691(99)$ & $676(98)$ & $686(98)$ & $670(98)$ \\
\hline Own latrine & $1321(96)$ & $664(95)$ & $656(95)$ & $670(95)$ & $662(97)$ \\
\hline Had a child potty & $61(4)$ & $28(4)$ & $35(5)$ & $27(4)$ & $30(4)$ \\
\hline Hectares of owned agricultural land (mean \pm SD) & $.427 \pm .025$ & $.407 \pm .029$ & $.411 \pm .030$ & $.420 \pm .028$ & $.459 \pm .054$ \\
\hline Household have own(\%) n & $N=1382$ & $N=696$ & $N=688$ & $N=703$ & $N=686$ \\
\hline Electricity & $784(57)$ & $408(59)$ & 405 (59) & $426(61)$ & $412(60)$ \\
\hline Refrigerator & $116(8.4)$ & $57(8.2)$ & $50(7.3)$ & $54(7.7)$ & $52(7.6)$ \\
\hline Mobile phone & $1188(86)$ & $591(85)$ & $582(85)$ & $600(85)$ & $593(86)$ \\
\hline Television & $416(30)$ & $225(32)$ & $210(31)$ & $187(27)$ & $203(30)$ \\
\hline Motorcycle & $100(7.2)$ & $47(6.8)$ & $35(5.1)$ & $53(7.5)$ & $32(4.7)$ \\
\hline
\end{tabular}

${ }^{\mathrm{a}} \mathrm{W}+\mathrm{S}+\mathrm{H}$ : in combination of water, sanitation, and hygiene intervention

${ }^{\mathbf{b}} \mathrm{W}+\mathrm{S}+\mathrm{H}+\mathrm{N}$ : in combination of water, sanitation hygiene and nutrition intervention

having some level of primary (DID: $8 \%, \mathrm{CI}: 1,15 \%$ ) and above primary education (DID: $10 \%, \mathrm{CI}: 4,17 \%$, and poorest mothers (Q1-DID: 16\%, CI: 7, 25\%) compared to mothers from richer quintiles (Table 3).

Over $95 \%$ of all intervention households had water and soap present near handwashing station at endline (Table $3)$. The greatest improvements from baseline to endline for the presence of soap and water occurred among uneducated mothers compared to educated mothers (DID: 84\%, CI: 75, 90\%) and the poorest mothers (Q1) compared to richer mothers (Q5-DID: 82\%, CI: 75, 90\%). We found that both maternal education and wealth quintiles modified the impact of the intervention on mother's hand cleanliness $(p<0.05)$ and presence of soap and water at the handwashing station $(p<0.05)$.

Visible feces on latrine slab or floors decreased for all wealth groups in the intervention households from baseline to endline. Among all quintiles, observed visible feces on latrine slabs was less common at endline $(-12$ to $-13 \%$ ) than baseline (31 to $58 \%$ ); a significant reduction occurred in the lowest two quintiles (Q1-DID: $-25 \%, \mathrm{CI}:-35,-15 \%$; Q2-DID: -34\%, CI: - 44, - 23\%) compared to households from the wealthiest quintile (DID: -1\%, CI: - 11, 8\%) (Table 4).

For all sanitation intervention households, mothers were more likely to report that their child defecated in potty at endline compared to baseline. Mothers having some primary education showed the greatest improvement (DID: $31 \%$, CI: $39,22 \%$ ) compared to mothers with no education and mothers with above primary education level. Improvements across all wealth quintiles were similar, with the lowest 4 quintiles showing the greatest improvement compared to the highest quintile (Table 4). Again, in adjusted models, we found that both maternal education and wealth quintiles significantly modified the impact of the intervention on these sanitation indicators $(p<0.05)$.

\section{Discussion}

In rural Bangladesh, when free-of cost WASH technologies were provided along with behavior change 
Table 2 Baseline characteristics of participants and households according to wealth quintiles

\begin{tabular}{|c|c|c|c|c|c|}
\hline \multirow[t]{3}{*}{ Characteristics } & \multicolumn{5}{|l|}{ n (\%) or mean \pm SD } \\
\hline & Lowest quintile (Q1) & 2nd quintile (Q2) & $3^{\text {rd }}$ quintile (Q3) & $4^{\text {th }}$ quintile (Q4) & Highest quintile (Q5) \\
\hline & $N=844$ & $N=820$ & $N=831$ & $N=836$ & $N=824$ \\
\hline Maternal age & $23.8 \pm 5.3$ & $24.5 \pm 5.3$ & $24.3 \pm 5.4$ & $23.5 \pm 5.4$ & $22.8 \pm 4.8$ \\
\hline \multicolumn{6}{|l|}{ Maternal education } \\
\hline No education & $267(32)$ & $206(25)$ & $93(11)$ & $52(6.2)$ & $20(2.4)$ \\
\hline Up-to primary & $374(44)$ & $318(39)$ & $314(38)$ & $229(27)$ & $92(11)$ \\
\hline Above primary & $203(24)$ & $296(36)$ & $424(51)$ & $555(66)$ & $712(86)$ \\
\hline \multicolumn{6}{|l|}{ Paternal education } \\
\hline No education & $486(58)$ & $354(43)$ & $252(30)$ & $129(15)$ & $39(4.7)$ \\
\hline Up to Primary & $264(31)$ & $285(35)$ & $293(35)$ & $281(34)$ & $130(16)$ \\
\hline Above primary & $92(11)$ & $179(22)$ & $283(34)$ & $424(51)$ & $654(79)$ \\
\hline Monthly household income (US\$) & $73 \pm 1.1$ & $88 \pm 1.5$ & $108 \pm 1.9$ & $147 \pm 3.1$ & $252 \pm 5.0$ \\
\hline People/Household & $3.5 \pm 0.04$ & $4.0 \pm 0.05$ & $4.4 \pm 0.06$ & $5.1 \pm 0.07$ & $6.5 \pm 0.09$ \\
\hline Children< 3 years /household & $0.22 \pm 0.014$ & $0.20 \pm 0.014$ & $0.18 \pm 0.014$ & $0.21 \pm 0.015$ & $0.29 \pm 0.014$ \\
\hline Children $<3$ years /compound & $0.82 \pm 0.03$ & $0.74 \pm 0.03$ & $0.64 \pm 0.03$ & $0.59 \pm 0.03$ & $0.55 \pm 0.03$ \\
\hline Own home & $803(95)$ & $803(98)$ & $822(99)$ & $831(99)$ & $821(100)$ \\
\hline Own latrine & $757(90)$ & $774(94)$ & $803(97)$ & $818(98)$ & $821(100)$ \\
\hline Had a child potty & $13(1.5)$ & $10(1.2)$ & $18(2.2)$ & $51(6.1)$ & $89(11)$ \\
\hline $\begin{array}{l}\text { Hectares of owned agricultural land } \\
(\text { mean } \pm \text { SD) }\end{array}$ & $0.13 \pm 0.014$ & $0.17 \pm 0.011$ & $0.22 \pm 0.010$ & $0.38 \pm 0.017$ & $0.80 \pm 0.039$ \\
\hline \multicolumn{6}{|l|}{ Household have own n (\%) } \\
\hline Electricity & $151(18)$ & $369(45)$ & $521(63)$ & $643(77)$ & $751(91)$ \\
\hline Refrigerator & $0(0)$ & $0(0)$ & $0(0)$ & $18(2.2)$ & $311(38)$ \\
\hline Mobile phone & $476(56)$ & $673(82)$ & $778(94)$ & $808(97)$ & 819 (99) \\
\hline Television & $5(0.6)$ & $51(6.2)$ & $201(24)$ & $362(43)$ & $622(75)$ \\
\hline Motorcycle & $0(0)$ & $0(0)$ & $5(0.6)$ & $42(5.0)$ & $220(26.7)$ \\
\hline
\end{tabular}

promotion, poorer households exhibited the greatest improvement in handwashing and sanitation uptake compared with wealthier households. This finding is consistent to results found in a non-randomized trial in rural Bangladesh, where households with the highest handwashing uptake, as evidenced by presence of lowcost soap alternative, were the ones that received handwashing promotion along with some sort of products and equipment support versus households that received handwashing promotion only [47].

The least educated households in the current study also exhibited greater improvements in handwashing and sanitation uptake compared with more educated households. This suggests that education level was less important for uptake of these preventive interventions, than lack of access to appropriate hardware and encouragement to use the hardware.

In this study, we report that the impacts of interventions were modified by maternal education and measures of socio- economic status. At baseline for both intervention and control groups, the poorest and the groups with the least education had the lowest levels of sanitation and handwashing behaviors and the wealthiest already had relatively higher levels. This distribution is typical for WASH indicators. The poorest and least educated improved the most because they also had the greatest scope for improvement. This pattern is also found in program context- communities with lowest levels of sanitation coverage have the highest improvements, while communities with already high baseline levels of coverage improve the least [27, 48]. Regardless of the degree of improvement over the intervention period for each wealth and education level, the final uptake rates for all wealth and education levels were high. These final uptake levels are higher than handwashing prevalence and latrine use rates recorded in most other handwashing and sanitation interventions reviews $[48,49]$.

Strengthening the supply-side of an intervention means ensuring access to appropriate hardware such as handwashing stations and durable and functional latrines. In Bangladesh, having a permanent designated 


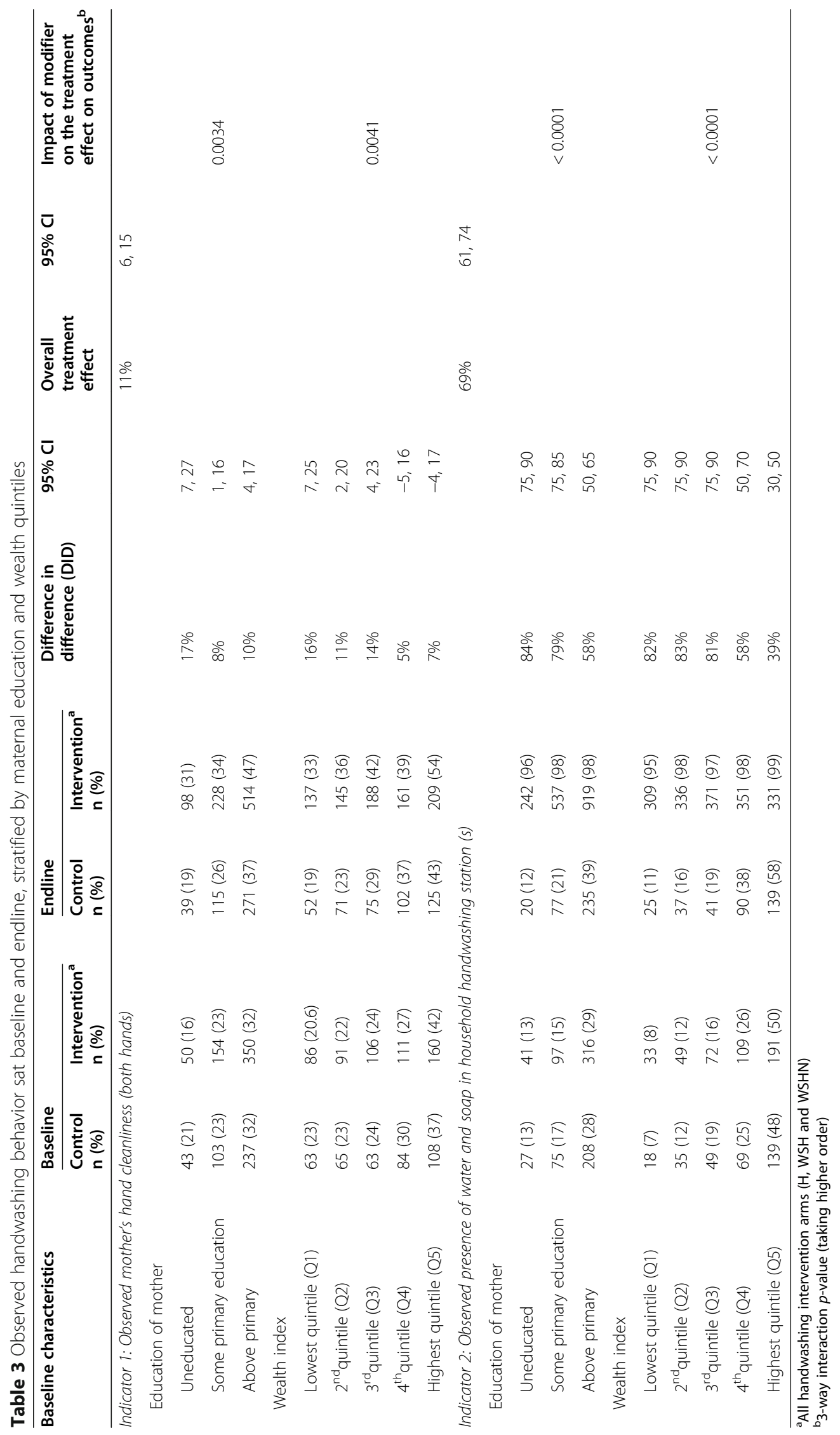


Table 4 Observed and reported sanitation behavior at baseline and endline, stratified by maternal education and wealth quintiles

\begin{tabular}{|c|c|c|c|c|c|c|c|c|c|}
\hline \multirow[t]{2}{*}{ Baseline characteristics } & \multicolumn{2}{|l|}{ Baseline } & \multicolumn{2}{|l|}{ Endline } & \multirow{2}{*}{$\begin{array}{l}\text { Difference } \\
\text { in difference } \\
\text { (DID) }\end{array}$} & \multirow[t]{2}{*}{$95 \% \mathrm{Cl}$} & \multirow{2}{*}{$\begin{array}{l}\text { Overall } \\
\text { treatment } \\
\text { effect }\end{array}$} & \multirow[t]{2}{*}{$95 \% \mathrm{Cl}$} & \multirow[b]{2}{*}{$\begin{array}{l}\text { Impact of } \\
\text { modifier } \\
\text { on the } \\
\text { treatment } \\
\text { effect on } \\
\text { outcomes }^{\text {b }}\end{array}$} \\
\hline & $\begin{array}{l}\text { Control } \\
\text { n (\%) }\end{array}$ & $\begin{array}{l}\text { Intervention }^{\mathrm{a}} \\
\mathrm{n}(\%)\end{array}$ & $\begin{array}{l}\text { Control } \\
\text { n (\%) }\end{array}$ & $\begin{array}{l}\text { Intervention }^{\mathrm{a}} \\
\mathrm{n}(\%)\end{array}$ & & & & & \\
\hline \multicolumn{7}{|c|}{ Indicator 3: Observed visible feces on latrine slab or floor } & $-21 \%$ & $-26,-16$ & \\
\hline \multicolumn{10}{|l|}{ Education of mother } \\
\hline Uneducated & $113(56)$ & $164(52)$ & $71(35.2)$ & $48(14)$ & $-16 \%$ & $-28,-05$ & & & \\
\hline Some primary education & $230(53)$ & $359(56)$ & $167(38.5)$ & $75(11)$ & $-31 \%$ & $-39,-22$ & & & 0.0001 \\
\hline Above primary & $339(46)$ & $496(46)$ & $235(32.0)$ & $151(14)$ & $-18 \%$ & $-24,-11$ & & & \\
\hline \multicolumn{10}{|l|}{ Wealth index } \\
\hline Lowest quintile (Q1) & $150(56)$ & $239(58)$ & $96(35.4)$ & $56(13)$ & $-25 \%$ & $-35,-15$ & & & \\
\hline $2^{\text {nd }}$ quintile (Q2) & $141(51)$ & $205(54)$ & $118(42.8)$ & $49(12)$ & $-34 \%$ & $-44,-23$ & & & \\
\hline $3^{\text {rd }}$ quintile (Q3) & $153(59)$ & $227(55)$ & $94(36.6)$ & $56(13)$ & $-19 \%$ & $-30,-09$ & & & $<0.0001$ \\
\hline $4^{\text {th }}$ quintile (Q4) & $123(45)$ & $221(53)$ & $97(35.1)$ & $57(13)$ & $-30 \%$ & $-40,-20$ & & & \\
\hline Highest quintile (Q5) & $115(40)$ & $127(31)$ & $68(23.5)$ & $56(14)$ & $-01 \%$ & $-11,08$ & & & \\
\hline \multicolumn{7}{|c|}{ Indicator 4: Reported last child defecation in potty or toilet among under 3 children } & $49 \%$ & 46,52 & \\
\hline \multicolumn{10}{|l|}{ Education of mother } \\
\hline Uneducated & $1(0.49)$ & $2(0.6)$ & $5(2.4)$ & $187(56)$ & $54 \%$ & 48,60 & & & \\
\hline Some primary education & $4(1.0)$ & $6(1.0)$ & $13(2.9)$ & $365(55)$ & $52 \%$ & 48,56 & & & $<0.0001$ \\
\hline Above primary & $15(2.0)$ & $13(1.2)$ & $92(12)$ & $627(58)$ & $46 \%$ & 42,50 & & & \\
\hline \multicolumn{10}{|l|}{ Wealth index } \\
\hline Lowest quintile (Q1) & $1(0.4)$ & $2(0.5)$ & $7(2.5)$ & $224(52)$ & $50 \%$ & 44,55 & & & \\
\hline $2^{\text {nd }}$ quintile (Q2) & $3(1.0)$ & $1(0.2)$ & $12(4.3)$ & $221(55)$ & $52 \%$ & 46,58 & & & \\
\hline $3^{\text {rd }}$ quintile (Q3) & 0 & $1(0.2)$ & $16(6.1)$ & $246(58)$ & $52 \%$ & 46,58 & & & $<0.0001$ \\
\hline $4^{\text {th }}$ quintile (Q4) & $6(2.2)$ & $9(2.1)$ & $17(6.2)$ & $255(60)$ & $54 \%$ & 48,60 & & & \\
\hline Highest quintile (Q5) & $10(3.4)$ & $8(2.0)$ & $58(20)$ & $233(57)$ & $39 \%$ & 31,46 & & & \\
\hline
\end{tabular}

${ }^{a}$ All sanitation intervention arms (S, WSH and WSHN)

${ }^{b} 3$-way interaction $p$-value (taking higher order)

handwashing place with soap and water present at that location, was associated with increased handwashing practices independent of socioeconomic status [13]. Furthermore, in many program contexts easy access to hardware does not negatively affect usage. In Zambia, people who paid lower prices for point-of-use water treatment solution were not less likely to use it relative to people who paid higher prices [50]. Similarly, in Kenya, women who received free bednets were equally likely to use them as women who paid for bednets [51].

Uptake is adversely affected when hardware support is suboptimal and scaled-up demand-driven or supplydriven programs are unable to ensure high quality infrastructure. Programs like CLTS may have improved coverage, but improved coverage may not equate to improved levels of usage in the context of large-scale programs [48]. The poorest commonly revert back to open defecation due to low-quality sanitation structures that are prone to collapse, or fill with no provision for emptying [52-54]. Many latrines built as part of CLTS are unimproved and shared; they do not effectively remove waste from the environment and are not sustainable [55].

In settings where the poorest lack financial resources to access health improving hardware, addressing supply constraints through free provision can support a proequity impact. However, free distribution may not always be possible and so subsidies [56-59] are one way of alleviating supply constraints and increasing demand among the poorest in scaled-up contexts. Subsidies or free provision of hardware can help the poorest move up the sanitation ladder [55].CLTS programs are increasingly exploring potential of financing mechanisms in order to reach the poorest and most marginalized [53, 54]. An experimental study conducted in Bangladesh compared hygienic latrine ownership between landless poor who were provided community motivation alone, supply-side market intervention alone, and subsidies [60]. The group that was provided subsidies increased latrine ownership the most. 
Strengthening the supply side of an intervention should not come at the cost of a weak approach to demand generation. Ensuring access to appropriate WASH hardware is a necessary, but generally not sufficient condition for uptake among the poorest. Behavior change promotion is also important to ensure continued use and habit formation for WASH behaviors.

There are important limitations to the conclusions that we can draw from this analysis. First, the study design does not allow us to specify which component of the WASH Benefits intervention design, the behaviorchange promotional activities or the WASH hardware provision, was more important to address equity. Although this is likely to vary by context, future studies could deploy experimental methods with varying levels of demand and supply-side components to understand which strategy would be most cost-effective in order to achieve equitable impact.

A second limitation is that the current analysis examined wealth and education inequity only. However, considerations of inequity outside the controlled setting of a randomized controlled trial may also affect communities including geographical, ethnic and gender inequity [61].

Finally, the WASH Benefits Bangladesh intervention occurred as part of an intensive scientific study with focused effort to maximize uptake. It is unclear whether interventions with the intensity typical of WASH programs could generate similar pro equity results. High level of CHP engagement in smaller clusters, and free or heavily subsidized provision of hardware to all participants are not scalable in most circumstances. Within scaled-up programs, one possible approach could be to have two distinct strategies-one focused on efficiency to reach the highest number of program beneficiaries, and a separate dedicated strategy for the poorest that can mimic the conditions of an efficacy trial. Such as approach has been employed by BRAC WASH program, where all participants received sanitation promotion, but the ultra-poor are provided free latrines once $80 \%$ coverage is reached in a community, and in areas where coverage is less than $80 \%$, the poor and ultra-poor are provided with subsidies [62]. Such a strategy is likely to be more effective in terms of improving equity of a program.

\section{Conclusion}

WASH interventions, whether supply-driven or demand-driven, have often adopted a strategy, whereby the people easiest to reach, the wealthier and the more educated populations, benefitted from coverage. However, this strategy has been inequitable. The WASH Benefits trial found that given sufficient support, the most vulnerable populations exhibit the greatest benefit from WASH interventions. What works for efficiency, that is reaching the greatest number of people with an intervention, may not work for equity, which requires reaching the most vulnerable. There are obvious trade-offs between health benefits, cost-effectiveness and costrecovery of WASH technologies [63]. While it is not possible to deploy an optimal strategy for all participants in a scale-up WASH program, this strategy of strengthening of the supply and demand sides of the intervention for the most vulnerable populations within a scaled-up program offers the potential for substantial improvements in overall program equity.

\section{Supplementary Information}

The online version contains supplementary material available at https://doi. org/10.1186/s12939-020-01353-7.

Additional file 1: Supplementary Table 1. Participants enrolment and retention

Additional file 2: Supplementary Table 2. Technological supplies and key behavioral messages for intervention households in the WASH Benefits trial, Bangladesh

\section{Abbreviations}

LMIC: Low and middle-income countries; DALY: Disability-adjusted life years; WASH: Water, sanitation and hygiene; CLTS: Community led total sanitation; IBM-WASH: Integrated behavioural model-water, sanitation and hygiene; W: Water; S: Sanitation; H: Handwashing; N: Nutrition; WSH: Water, sanitation and handwashing; WASN: Water, sanitation, handwashing and nutrition; CHP: Community health promoter; PCA: Principal component analysis; Q: Quintiles; DID: Difference in difference; GLM: Generalized linear models

\section{Acknowledgements}

The authors acknowledge the WASH Benefits study collaborators and acknowledge the cooperation of the study households, community health promoters (CHPs), field workers and communities that were visited several times for intervention delivery and data collection.

\section{Authors' contributions}

SMP, RA and MHM conducted data analysis; SMP and MJR interpreted the results and drafted the manuscript as primary author and co-primary author with the listed co-authors. SPL provided conceptual guidance for data analysis and manuscript development. MR, SA, RA, LU, FJ, PJW provided support for tools preparation, validation, data collection and analysis. All authors provided feedback and read and approved the manuscript.

\section{Funding}

This research study was funded by the Bill \&Melinda Gates Foundation grant OPPGD759 through the University of California Berkeley. icddr,b acknowledges with gratitude the commitment of the Bill \&Melinda Gates Foundation to its research efforts. Icddr,b is also grateful to the Governments of Bangladesh, Canada, Sweden and the UK for providing core/unrestricted support.

Availability of data and materials

Data can be made available through the authors.

\section{Ethics approval and consent to participate}

All households provided written informed consent at enrollment. The protocol was reviewed and approved by human subjects review committees at the icddr,b, at the University of California, Berkeley and at the Stanford University.

\section{Consent for publication}

All co-authors have reviewed this version of the manuscript and provided consent for manuscript submission. 


\section{Competing interests}

We declare no competing interests.

\section{Author details Centre for Diarrhoeal Disease Research, Bangladesh (icddr,b), Dhaka, Interventions Program, Department of International Health, Johns Hopkins Bloomberg School of Public Health, Baltimore, MD, USA. ${ }^{5}$ Division of CA, USA. \\ Received: 28 August 2020 Accepted: 9 December 2020 \\ Published online: 06 January 2021}

${ }^{1}$ Environmental Intervention Unit, Infectious Diseases Division, International Bangladesh. ${ }^{2}$ University of Pennsylvania, Philadelphia, PA, USA. ${ }^{3}$ Department of Statistics, University of Barishal, Barishal, Bangladesh. ${ }^{4}$ Social and Behavioral Infectious Diseases and Geographic Medicine, Stanford University, Stanford,

\section{References}

1. Marmot M, Friel S, Bell R, Houweling TA, Taylor S, Health CoSDo. Closing the gap in a generation: health equity through action on the social determinants of health. Lancet. 2008;372(9650):1661-9.

2. Barros AJ, Ronsmans C, Axelson H, Loaiza E, Bertoldi AD, França GV, et al. Equity in maternal, newborn, and child health interventions in countdown to 2015: a retrospective review of survey data from 54 countries. Lancet. 2012:379(9822):1225-33.

3. Meheus F, Van Doorslaer E. Achieving better measles immunization in developing countries: does higher coverage imply lower inequality? Soc Sci Med. 2008;66(8):1709-18

4. Victora CG, Joseph G, Silva IC, Maia FS, Vaughan JP, Barros FC, et al. The inverse equity hypothesis: analyses of institutional deliveries in 286 national surveys. Am J Public Health. 2018;108(4):464-71.

5. Rheingans R, Kukla M, Faruque ASG, Sur D, Zaidi AK, Nasrin D, et al. Determinants of household costs associated with childhood diarrhea in 3 South Asian settings. Clin Infect Dis. 2012;55(suppl_4):S327-S35.

6. Barros FC, Victora CG, Scherpbier R, Gwatkin D. Socioeconomic inequities in the health and nutrition of children in low/middle income countries. Rev Saude Publica. 2010;44:1-16.

7. Robinson A. Sanitation finance in rural Cambodia; 2012

8. UNICEF. United Nations Children's Fund Narrowing the gaps: the power of investing in the poorest children. New York: UNICEF; 2017. (https://www. unicef.org/publications/index_96534.html).

9. Prüss-Ustün A, Wolf J, Bartram J, Clasen T, Cumming O, Freeman MC, et al. Burden of disease from inadequate water, sanitation and hygiene for selected adverse health outcomes: an updated analysis with a focus on low-and middle-income countries. Int J Hyg Environ Health. 2019;222(5):765-77.

10. Armah FA, Ekumah B, Yawson DO, Odoi JO, Afitiri A-R, Nyieku FE. Access to improved water and sanitation in sub-Saharan Africa in a quarter century. Heliyon. 2018;4(11):e00931.

11. WHO, UNICEF. Progress on household drinking water, sanitation and hygiene 2000-2017: special focus on inequalities. New York: WHO; 2019.

12. Rahman MS, Rahman MM, Gilmour S, Swe KT, Abe SK, Shibuya K. Trends in, and projections of, indicators of universal health coverage in Bangladesh, 1995-2030: a Bayesian analysis of population-based household data. Lancet Glob Health. 2018;6(1):e84-94.

13. Luby SP, Halder AK, Tronchet C, Akhter S, Bhuiya A, Johnston RB. Household characteristics associated with handwashing with soap in rural Bangladesh. Am J Trop Med Hyg. 2009;81(5):882-7.

14. Luby SP, Halder AK. Associations among handwashing indicators, wealth, and symptoms of childhood respiratory illness in urban Bangladesh. Tropical Med Int Health. 2008;13(6):835-44.

15. Kumar S, Loughnan L, Luyendijk R, Hernandez O, Weinger M, Arnold F, et al. Handwashing in 51 countries: analysis of proxy measures of handwashing behavior in multiple indicator cluster surveys and demographic and health surveys, 2010-2013. Am J Tropl Med Hyg. 2017;97(2):447-59.

16. Schmidt WP, Aunger R, Coombes Y, Maina PM, Matiko CN, Biran A, et al. Determinants of handwashing practices in Kenya: the role of media exposure, poverty and infrastructure. Tropical Med Int Health. 2009:14(12):1534-41.

17. Rosa G, Clasen T. Estimating the scope of household water treatment in lowand medium-income countries. Am J Trop Med Hyg. 2010;82(2):289-300.

18. Geremew A, Damtew YT. Household water treatment using adequate methods in sub-Saharan countries: evidence from 2013-2016 demographic and health surveys. J Water Sanit Hyg Dev. 2020;10(1):66-75.
19. Jenkins MW, Sugden S. Rethinking sanitation: Lessons and innovation for sustainability and success in the new millennium (No. HDOCPA-2006-27). Human Development Report Office (HDRO), United Nations Development Programme (UNDP); 2006.

20. Trémolet S, Kolsky P, Perez E. Financing on-site sanitation for the poor: a six country comparative review and analysis. Washington, DC: World Bank; 2010

21. Barnard S, Routray P, Majorin F, Peletz R, Boisson S, Sinha A, et al. Impact of Indian Total sanitation campaign on latrine coverage and use: a crosssectional study in Orissa three years following programme implementation. PLoS One. 2013;8(8):e71438.

22. Coffey D, Gupta A, Hathi P, Khurana N, Spears D, Srivastav N, et al. Revealed preference for open defecation. Econ Polit Wkly. 2014;49(38):43.

23. Coffey D, Gupta A, Hathi P, Spears D, Srivastav N, Vyas S. Culture and the health transition: understanding sanitation behavior in rural North India. In: International Growth Centre Working Paper, April; 2015.

24. Foster T, Furey S, Banks B, Willetts J. Functionality of handpump water supplies: a review of data from sub-Saharan Africa and the Asia-Pacific region. Int J Water Resour Dev. 2020;36(5):855-69.

25. Alzúa ML, Djebbari H, Pickering AJ. A community-based program promotes sanitation. Econ Dev Cult Chang. 2020;68(2):357-90.

26. Pattanayak SK, Yang J-C, Dickinson KL, Poulos C, Patil SR, Mallick RK, et al. Shame or subsidy revisited: social mobilization for sanitation in Orissa, India. Bull World Health Organ. 2009;87:580-7.

27. Harvey PA. Zero subsidy strategies for accelerating access to rural water and sanitation services. Water Sci Technol. 2011;63(5):1037-43.

28. Cameron L, Olivia S, Shah M. Scaling up sanitation: evidence from an RCT in Indonesia. J Dev Econ. 2019;138:1-16.

29. Slekiene J, Mosler H-J. Characterizing the last latrine nonowners in rural Malawi. Am J Trop Med Hyg. 2018;98(1):295-9.

30. O'Loughlin R, Fentie G, Flannery B, Emerson PM. Follow-up of a low cost latrine promotion programme in one district of Amhara, Ethiopia: characteristics of early adopters and non-adopters. Tropical Med Int Health. 2006;11(9):1406-15.

31. Holm R, Tembo M, Njera D, Kasulo V, Malota M, Chipeta W, et al. Adopters and non-adopters of low-cost household latrines: a study of corbelled pit latrines in 15 districts of Malawi. Sustainability. 2016:8(10):917.

32. Njuguna J. Progress in sanitation among poor households in Kenya: evidence from demographic and health surveys. BMC Public Health. 2019; 19(1):135.

33. Cole B, DeGabriele J, Ho G, Anda M. Exploring the utility of diffusion theory to evaluate social marketing approaches to improve urban sanitation in Malawi. J Water Sanit Hyg Dev. 2015;5(2):289-300.

34. Peletz R, Cock-Esteb A, Ysenburg D, Haji S, Khush R, Dupas P. Supply and demand for improved sanitation: results from randomized pricing experiments in rural Tanzania. Environ Sci Technol. 2017;51(12):7138-47.

35. Langford $\mathrm{R}$, Panter-Brick $C$. A health equity critique of social marketing: where interventions have impact but insufficient reach. Soc Sci Med. 2013; 83:133-41.

36. Wymer W. Developing more effective social marketing strategies. J Soc Mark. 2011;1(1):17-31.

37. Harris JR, Patel MK, Juliao P, Suchdev PS, Ruth $L$, Were $V$, et al. Addressing inequities in access to health products through the use of social marketing, community mobilization, and local entrepreneurs in rural Western Kenya. Int J Popul Res. 2012;2012:1-9.

38. Noor AM, Amin AA, Akhwale WS, Snow RW. Increasing coverage and decreasing inequity in insecticide-treated bed net use among rural Kenyan children. PLoS Med. 2007:4(8):e255.

39. Freeman MC, Quick RE, Abbott DP, Ogutu P, Rheingans R. Increasing equity of access to point-of-use water treatment products through social marketing and entrepreneurship: a case study in western Kenya. J Water Health. 2009;7(3):527-34

40. Luby SP, Rahman M, Arnold BF, Unicomb L, Ashraf S, Winch PJ, et al. Effects of water quality, sanitation, handwashing, and nutritional interventions on diarrhoea and child growth in rural Bangladesh: a cluster randomised controlled trial. Lancet Glob Health. 2018;6(3):e302-e15.

41. Rahman M, Ashraf S, Unicomb L, Mainuddin A, Parvez SM, Begum F, et al. WASH benefits Bangladesh trial: system for monitoring coverage and quality in an efficacy trial. Trials. 2018;19(1):360.

42. Unicomb L, Begum F, Leontsini E, Rahman M, Ashraf S, Naser AM, et al. WASH benefits Bangladesh trial: management structure for achieving high coverage in an efficacy trial. Trials. 2018;19(1):359. 
43. Dreibelbis R, Winch PJ, Leontsini E, Hulland KR, Ram PK, Unicomb L, et al. The integrated behavioural model for water, sanitation, and hygiene: a systematic review of behavioural models and a framework for designing and evaluating behaviour change interventions in infrastructure-restricted settings. BMC Public Health. 2013;13(1):1015.

44. Pickering AJ, Ercumen A, Arnold BF, Kwong LH, Parvez SM, Alam M, et al. Fecal indicator bacteria along multiple environmental transmission pathways (water, hands, food, soil, flies) and subsequent child diarrhea in rural Bangladesh. Environ Sci Technol. 2018;52(14):7928-36.

45. Hutton G, Chase $C$. The knowledge base for achieving the sustainable development goal targets on water supply, sanitation and hygiene. Int $J$ Environ Res Public Health. 2016;13(6):536.

46. Arnold BF, Null C, Luby SP, Unicomb L, Stewart CP, Dewey KG, et al. Clusterrandomised controlled trials of individual and combined water, sanitation, hygiene and nutritional interventions in rural Bangladesh and Kenya: the WASH Benefits study design and rationale. BMJ Open. 2013;3(8):1-17.

47. Ashraf S, Nizame FA, Islam M, Dutta NC, Yeasmin D, Akhter S, et al. Nonrandomized trial of feasibility and acceptability of strategies for promotion of soapy water as a handwashing agent in rural Bangladesh. Am J Trop Med Hyg. 2017;96(2):421-9.

48. Garn JV, Sclar GD, Freeman MC, Penakalapati G, Alexander KT, Brooks P, et al. The impact of sanitation interventions on latrine coverage and latrine use: a systematic review and meta-analysis. Int J Hyg Environ Health. 2017;220(2):329-40.

49. Freeman MC, Stocks ME, Cumming O, Jeandron A, Higgins JP, Wolf J, et al. Systematic review: hygiene and health: systematic review of handwashing practices worldwide and update of health effects. Tropical Med Int Health. 2014;19(8):906-16.

50. Ashraf N, Berry J, Shapiro JM. Can higher prices stimulate product use? Evidence from a field experiment in Zambia. Am Econ Rev. 2010;100(5):2383-413.

51. Cohen J, Dupas P. Free distribution or cost-sharing? Evidence from a randomized malaria prevention experiment. Q J Econ. 2010;125(1):1.

52. Odagiri M, Muhammad Z, Cronin AA, Gnilo ME, Mardikanto AK, Umam K, et al. Enabling factors for sustaining open defecation-free communities in rural Indonesia: a cross-sectional study. Int J Environ Res Public Health. 2017; 14(12):1572.

53. Robinson A, Gnilo M. Promoting choice: smart finance for rural sanitation development. In: Sustainable Sanitation for All: Experiences, Challenges and Innovations; 2016.

54. Robinson A, Gnilo M. Beyond ODF: a phased approach to rural sanitation development. In: Sustainable Sanitation for All: Experiences, challenges, and innovations; 2016. p. 155.

55. Galvin M. Talking shit: is community-led Total sanitation a radical and revolutionary approach to sanitation? Wiley Interdiscip Rev Water. 2015;2(1):9-20.

56. Dupas P, Hoffmann V, Kremer M, Zwane AP. Targeting health subsidies through a nonprice mechanism: a randomized controlled trial in Kenya. Science. 2016;353(6302):889-95.

57. Dupas P. Health behavior in developing countries. Annu Rev Econ. 2011; 3(1):425-49.

58. Dupas P. Getting essential health products to their end users: subsidize, but how much? Science. 2014;345(6202):1279-81.

59. Kremer M, Holla A. Pricing and access: lessons from randomized evaluations in education and health. In: What Works in Development: Thinking Big and Thinking Small; 2009. p. 91-129.

60. Guiteras R, Levinsohn J, Mobarak AM. Encouraging sanitation investment in the developing world: a cluster-randomized trial. Science. 2015;348(6237):903-6.

61. Waage J, Banerji R, Campbell O, Chirwa E, Collender G, Dieltiens V, et al. The millennium development goals: a cross-sectoral analysis and principles for goal setting after 2015: lancet and London international development Centre commission. Lancet. 2010:376(9745):991-1023.

62. Akter T, Ali AR, Dey NC. Transition overtime in household latrine use in rural Bangladesh: a longitudinal cohort study. BMC Public Health. 2014;14(1):721.

63. Ritter M, Camille E, Velcine C, Guillaume R-K, Lantagne D. Optimizing household chlorination marketing strategies: a randomized controlled trial on the effect of price and promotion on adoption in Haiti. Am J Trop Med Hyg. 2017;97(1):271-80.

\section{Publisher's Note}

Springer Nature remains neutral with regard to jurisdictional claims in published maps and institutional affiliations.

\section{Ready to submit your research? Choose BMC and benefit from:}

- fast, convenient online submission

- thorough peer review by experienced researchers in your field

- rapid publication on acceptance

- support for research data, including large and complex data types

- gold Open Access which fosters wider collaboration and increased citations

- maximum visibility for your research: over $100 \mathrm{M}$ website views per year

At BMC, research is always in progress.

Learn more biomedcentral.com/submissions 